\title{
TRAUMATIC LESIONS OF INTERNAL SAPHENOUS NERVE AND BRANCHES
}

\author{
Flávio Freinkel Rodrigues', Issac Skartz' , Diego Cassol Dozza², \\ Maurício Moscovici², Mendel Suchmacher ${ }^{3}$
}

\begin{abstract}
Objective: To show a rare lesion that sometimes simulates vascular disorder of the lower extremities. Method: Three patients were operated and the follow-up period was eight months, the surgical technique was neurotomy of the infrapatellar and descendent branches. Results: In two cases there were almost total pain resolution, and in other case improvement only. Conclusion: Surgical treatment yields good results in this type of internal saphenous nerve lesion, and could be useful as an alternative to conservative treatment.
\end{abstract}

KEY WORDS: internal saphenous nerve, iatrogenic nerve injury, neurotomy.

\section{Lesões traumáticas do nervo safeno interno e seus ramos}

Resumo - Objetivo: Apresentar lesões raras do nervo safeno interno interno, que muitas vezes, simulam doenças vasculares dos membros inferiores. Método: Três pacientes foram operados e acompanhados por um período de oito meses. A técnica cirúrgica consistiu na neurotomia dos ramos infrapatelar e descendente do nervo safeno interno. Resultados: Nos dois primeiros casos houve quase desaparecimento total da dor em pouco tempo e no terceiro apenas melhora. Conclusão: $O$ tratamento cirúrgico dá bons resultados neste tipo de lesão do nervo safeno interno e poderia ser útil como alternativa ao tratamento conservador.

PALAVRAS-CHAVE: nervo safeno interno, lesão neural iatrogênica, neurotomia.

Internal saphenous nerve is femoral nerve's longest branch, and is much subject to trauma due to its traject and susceptibility to compression from anatomically related structures ${ }^{1}$. Traumatic injuries on this nerve and its branches during knee joint surgical procedures are common, specially during meniscus, femoral artery and femoral vein related procedures. Among internal saphenous nerve itself and corresponding branches, infra-patelar branch is the most commonly compromised nerve during knee orthopedical interventions. According to Coppel and Thompson ${ }^{2}$, infra-patelar branch is traumatized in two thirds of meniscus surgeries. During surgery for venous insufficiency, lesion can occur on internal saphenous nerve trunk, while saphenous vein is being submitted to traction. A mild sensitivity loss occurs, but in some cases there is formation of painful neuroma. This condition must be differentiated from internal saphenous nerve neuropathy, which is caused either by compression of this nerve inside Hunter's canal, or by contiguous great saphen- ous vein inflammation. Neuropathy of internal saphenous nerve's branches, i.e., infra-patelar branch and medial cutaneous nerve of the leg, is characterized by continuous pain on the medial aspect of the knee. Paresthesia associated with unpleasant sensation complaints during lower limb movement, were reported by the three patients. All of them presented superficial hypoesthesia on infrapatelar branch territory, as well as a positive Tinnel sign. Internal saphenous nerve is a femoral nerve branch, which passes posteriorly and medially to the femoral triangle, to enter Hunter's canal, after a short length.

This canal is roofed by a fascia and the sartorius muscle, bounded frontally and laterally by vastus medialis muscle, and posteriorly by adductor longus muscle. Immediately after its exit form Hunter's canal, internal saphenous nerve originates the infra-patellar branch and the medial cutaneous nerve of the leg. The latter escorts great saphenous vein along its traject in the leg. Internal saphenous nerve innervates the medial aspect of the knee.

\footnotetext{
${ }^{1}$ Neurosurgery Dpt. of Universidade Federal do Rio de Janeiro Medicine Faculty; Instituto de Neurologia Deolindo Couto Neurosurgery Service, Rio de Janeiro RJ, Brazil; ${ }^{2}$ Head of Anatomy Subject, Universidade Federal do Rio de Janeiro, Rio de Janeiro RJ, Brazil. Honorary Emeritus Professor of the AAA; ${ }^{3}$ Professor of Faculdade de Medicina de Teresópolis, Rio de Janeiro RJ, Brazil. Member of the American College of Physicians.
} 
This nerve is susceptible to direct trauma, along its traject under the distal fascia of saphenous tunnel ${ }^{3}$ (Fig 1).

Besides presenting our preliminary results with these three cases, the aim of this paper is to draw attention to the above quoted lesions, often underrecognized and underdiagnosed among Brazilian physicians.

\section{METHOD}

This is a retrospective study based on a series of three patients who were evaluated, treated and followed during eight months approximately, at Instituto de Neurologia Deolindo Couto Peripheral Nerve Outpatient service of Universidade Federal do Rio de Janeiro. Two male patients and one female patient, averaged 54 years old. All patients from this series presented iatrogenic injury of internal saphenous nerve branches. The two male patients were submitted to surgical arthroscopy for meniscus surgery through an incision on the medial aspect of the knee, and the female patient to a total knee replacement surgery through incision on the medial aspect of the joint.

All patients were surgically treated using the same technique, i.e., neurotomy through an incision on the medial aspect of the knee (Fig 2), with microscopical dissection at internal saphenous nerve bifurcation into its branches (infra-patellar branch and medial cutaneous nerve of the leg) followed by sectioning of both (Zeiss Microscope, 20x magnifying lens). In one case, a neuroma was found. In the other two cases where neuroma was not found, stumps were tied with absorbable suture and placed under local musculature. In the neuroma case, the lesion was sectioned and the stump submitted to the same conduct. Pain graduation was performed through comparative Visual Analogic Scale analysis ${ }^{3}$. The three patients signed the Informed Consent, where surgery objectives, as well as potential benefits and risks, were detailed.

\section{RESULTS}

There were two results considered as good and one as regular, from all three presented cases. The good results corresponded to a $90 \%$ improvement of painful symptoms with analgesic medication withdrawal. Only a small hypoesthesia area remained over the internal aspect of crural lower third and knee medial aspect. Grade 1 (Visual Analogic Scale).

There was a $50 \%$ improvement of painful symptoms for the regular result patient, who still was using analgesic medication at the eighth month of follow-up. Grade 1 (Visual Analogic Scale).

\section{DISCUSSION}

According to McGinty ${ }^{4}$, arthroscopy has revolutionized knee surgery along the last three decades. Applicabilities and indications of arthroscopic procedures have been presenting an important momentum. But, despite being minimally invasive, this technique presents its share of mor- bidity. Kim et al. ${ }^{5}$ report neurovascular complications associated with its corresponding equipment. In another important review which included 2640 arthroscopic procedures, Sherman et al. ${ }^{6}$ documented 15 cases of infra-patellar branch lesion - an internal saphenous nerve branch -, corresponding to a $0.6 \%$ incidence. In 1995, Mochida and Kikuchi $^{7}$ also reviewed 81 knee orthopedic procedures and found 18 internal saphenous nerve lesions cases (22.2\%), presenting with painful anesthesia on infra-patellar branch distribution. According to Vincent and Stanisch ${ }^{8}$, nerves are not the sole structures compromised during knee orthopedic procedures, but also genicular artery, popliteal artery and superficial femoral artery (or femoral artery) branches are amenable to trauma. Fowler ${ }^{9}$ reported that, even though tourniquet use during surgery turns techinque employment easier, it can cause ischemia on internal saphenous nerve trunk. This author also demonstrated nerve condution block, and periaxonal edema which resulted in myelin sheath edema, due to nerve compression associ-

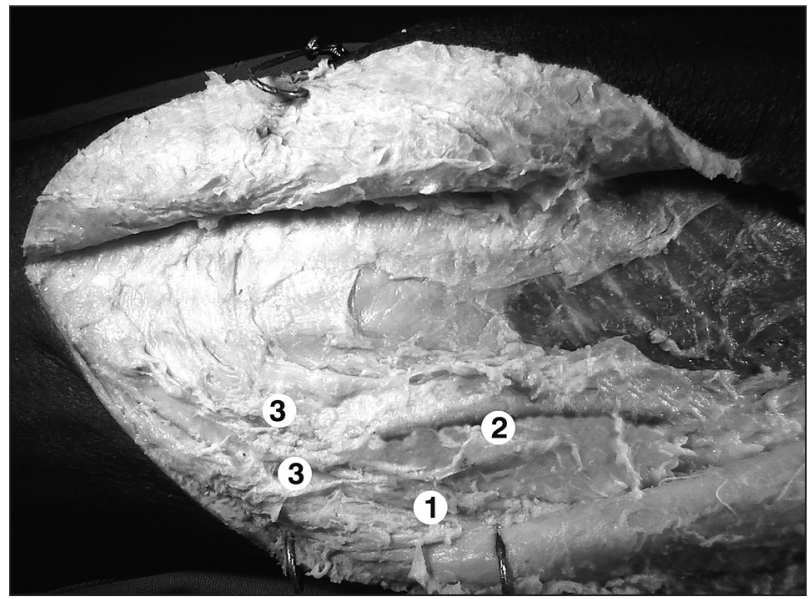

Fig 1. The following structures are visualized, in closer approximation: [1] internal saphenous nerve main trunk; [2] great saphenous vein; [3] infrapatellar branches.

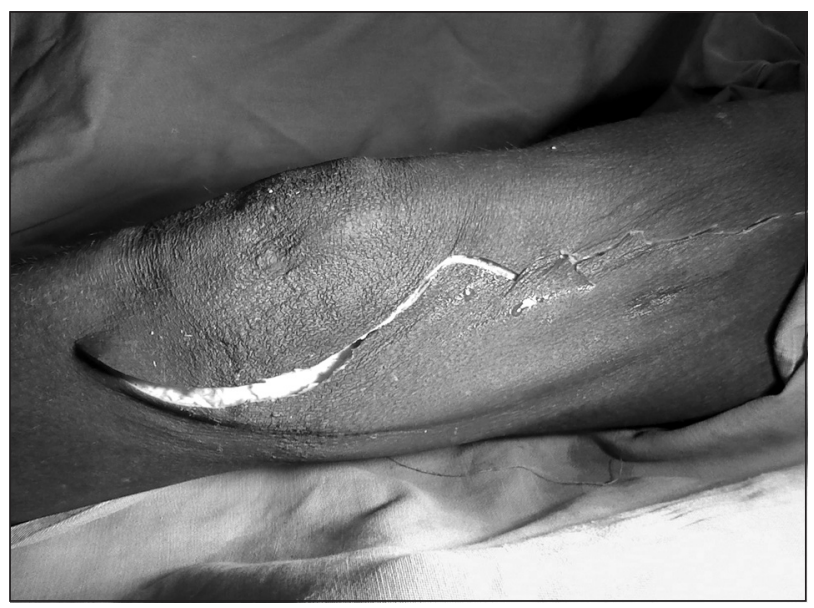

Fig 2. Incision for surgical approach of internal saphenous nerve and branches, is shown in a corpse anatomical dissection. 
ated to tourniquet use during one to three hours. Conduct and prognosis vary according to trauma intensity.

According to Swanson ${ }^{10}$, pre-patelar disesthesia frequency after meniscus excision has been being underestimated. This author has found a $63.2 \%$ rate of this type of complication, in an analysis of 87 patients submitted to this procedure and followed during at least six months. Six months after the intervention, the condition persisted in $44.4 \%$ of subjects. Small ${ }^{11}$ comparatively studied two great series of patients submitted to knee arthroscopy. In the first series, which was retrospective and involved 3034 arthroscopic procedures, this author reported 30 cases of internal saphenous nerve lesion (1\%), six of common fibular nerve lesion $(0.2 \%)$ and three cases of vascular lesions $(0.1 \%)$. In the second series, which was prospective and involved 8791 patients submitted to knee arthroscopy, the author reported an only case, associated to internal saphenous nerve lesion (0.4\%). Small" accounted this results improvement to a greater expertise of the surgeons with the technique. Conduct and prognosis regarding this type of lesion vary according to the severity of nerve's lesion, which ranges from neuropraxy to neurotmesis. These lesions improve after a period of days to weeks, in most patients. Patients must be instructed to avoid body positioning which might cause compression of the compromised nerve. Neurological assessment is warranted, if symptoms persist for a longer period.

According to Abram and Froimson ${ }^{12}$, in order to prevent intra-operatory complications due to the arthroscope, surgeons must perform the technique cautiously and know the anatomy of the region ${ }^{13,14}$. Perfect visualization of all instruments during the surgical procedure is also advisable, for most part of these complications is avoidable.

In this small series, patients were selected among those with traumatic injury on internal saphenous nerve or its branches who did not respond to medical or fisiotherapic treatment. For this reason, conservative and surgical results comparison is not feasible. Nevertheless, surgical intervention should always be a possibility when- ever there is neuroma diagnosis. It is important to stress that these are preliminary results, due to the small number of patients.

In conclusion, this type of traumatic injury on internal saphenous nerve and its branches, must be diagnosed and, in some instances, surgically approached. Results obtained through neurotomy are good, according to literature review and to our preliminary study. This form of treatment is an option for those cases in which conservative approach did not yield satisfactory results.

\section{REFERENCES}

1. Tranier S, Durey A, Chevallier B, Liot F. Value of somatosensory evoked potentials in saphenous entrapment neuropathy. J Neurol Neurosurg Psychiatry 1992;55:461-465.

2. Copel HP, Thompson WAL. Knee pain due to saphenous nerve entrapment. N Engl J Med 1960;263:351-353.

3. Lippitt AB. Neuropathy of the saphenous nerve as a cause of knee pain. Bull Hosp Jt Dis 1993;52:31-33.

4. McGinty JB, Johnson LL, Jackson RW, McBryde AM, Goodfellow JW. Uses and abuses of arthroscopy: a symposium. J Bone Joint Surg Am, 1992;74:1563-1577.

5. Kim DH, Kline DG. Management and results of peroneal nerve lesions. Neurosurgery 1996;39:312-319.

6. Sherman OH, Fox JM, Snyder SJ, Del Pizzo W, et al. Arthroscopy - "noproblem surgery": an analysis of complications in two thousand six hundred and forty cases. J Bone Joint Surg Am 1986;68:256-265.

7. Mochida H, Kikuchi S. Injury to infrapatellar branch of saphenous nerve in arthroscopic knee surgery. Clin Orthop Relat Res 1995 (Nov);320: 88-94.

8. Vincent GM, Stanish WD. False aneurysm after arthroscopic meniscectomy: a report of two cases. J Bone Joint Surg Am 1990;72:770-772.

9. Fowler TJ, Danta G, Gilliatt RW. Recovery of nerve conduction after a pneumatic tourniquet: observations on the hind-limb of the baboon. J Neurol Neurosurg Psychiatry 1972;35:638-647.

10. Swanson AJ. The incidence of prepatellar neuropathy following medial meniscectomy. Clin Orthop Relat Res 1983;181(Dec):151-153.

11. Small NC. Complications in arthroscopic surgery of the knee and shoulder. Orthopedics 1993;16:985-988.

12. Abram LJ, Froimson AI. Saphenous nerve injury: an unusual arthroscopic complication. Am J Sports Med 1991;19:668-669.

13. Warwick and Williams. Gray's anatomy. $35^{\text {th }}$ British Edition. Philadelphia: WB Saunders Company, 1973. (used as consultation source for English version).

14. Hollinshead WH. Anatomy for surgeons. New York: Hoeber Medical Division. Harper \& Row Publishers, 1969 (used as consultation source for English version). 